\title{
A interlocução do Serviço Social e os meios de comunicação: aproximações reflexivas
}

\author{
The Interlocution of Social Work and the media: reflective approaches
}

\author{
Jéssica Degrandi Soares* \\ Rosa Maria Castilhos Fernandes**
}

\section{Resumo:}

O artigo considera, a partir do referencial utilizado, que a interlocução do Serviço Social com os meios de comunicação, em especial as rádios comunitárias, pode-se constituir enquanto um espaço de enfrentamento e de defesa dos direitos sociais da classe trabalhadora, e evidencia a necessidade de se fomentar a discussão sobre a articulação destas áreas. Para tanto, traz a discussão do Estado Social e a sua relação com os meios de comunicação. $O$ acesso à informação, garantido nas legislações das políticas sociais, e a potencialização dos direitos sociais por meio das mídias alternativas, são caminhos a serem explorados pelos assistentes sociais, e isso pode ser evidenciado a partir das instâncias de defesa da categoria e também a partir de discussões ampliadas nos mais diversos espaços de participação social.

Palavras-chave: Serviço social. Comunicação. Mídias alternativas. Direitos sociais. Estado social.

\begin{abstract}
:
This article considers, from the reference used, that the Social Work with the communication media, especially the community radio stations, might constitute a space for confrontation and defense of the social rights of the working class, and it shows the need to foster discussion on the articulation of these areas. To do so, it brings the discussion of the Social State and its relationship with the media. Access to information guaranteed in the social legislations, and the potentialization of social rights through alternative media are ways to be explored by social workers, from expanded discussions in the most diverse spaces of social participation.
\end{abstract}

Keywords: Social work. Communication. Alternative media. Social rights. Social state.

\footnotetext{
* Doutoranda no Programa de Pós-Graduação em Serviço Social na PUCRS e integrante do Grupo de Estudos em Juventudes e Políticas Públicas - GEJUP (PUCRS). Integra o Núcleo de Estudos, Pesquisa e Extensão em Serviço Social, Mídia, Cultura e Questão Social (NEPMQS/UFSM).

** Doutorado em Serviço Social pela Pontifícia Universidade Católica do Rio Grande do Sul (2008), com estágio de doutorado no Instituto de Psicologia e Ciências da Educação da Universidade do Porto-Portugal. Professora Adjunta do Departamento de Serviço Social e Vice Coordenadora do Programa de Pós Graduação em Política Social e Serviço Social /Instituto de Psicologia da Universidade Federal do Rio Grande do Sul(UFRGS).
} 


\section{Introdução}

A condição da desestruturação das políticas sociais e, consequentemente, a corrosão dos direitos sociais e a precarização da vida da classe trabalhadora, é uma realidade brasileira que se intensifica. Esta retirada dos direitos sociais que vêm sendo posta em curso se constitui enquanto uma necessidade do sistema capitalista e protagonizada por ideários liberais, assim como, por valores neoconservadores, que caracterizam este final da segunda década do século XXI. Da mesma forma os meios de comunicação possuem um papel fundamental e estratégico na disseminação desta engrenagem de produção e reprodução do capital. E é por isso que partiu-se da perspectiva de que a resistência por meio da mobilização da população é necessária e deve ser constantemente reforçada por todos os segmentos desta sociedade, que compreendem o quanto os direitos sociais adquiridos pela classe trabalhadora, são fundamentais para o desenvolvimento econômico e social de uma sociedade onde impera a desigualdade social.

Nesse processo, identificam-se as múltiplas expressões da questão social, que é inerente à sociabilidade capitalista resultando nas relações sociais oriundas deste sistema. Ela se caracteriza desde a desigualdade social até as situações de violação dos direitos sociais vivenciadas por significativa parcela da população, assim como, suas resistências que se manifestam nos movimentos sociais, nas instâncias democráticas e participativas constantemente ameaçadas, enfim nas estratégias de lutas, da classe trabalhadora, que têm como bandeira a defesa e ampliação dos direitos humanos. Entretanto, é preciso reconhecer que a questão social é mais do que "as expressões da pobreza, miséria e exclusão. Condensa a banalização do humano que atesta à radicalidade da alienação e a invisibilidade do trabalho social e dos sujeitos que o realizam na era do capital fetiche." (IAMAMOTO, 2015, p. 125). Portanto, a existência da subordinação humana às coisas e ao capital mercadoria, caracteriza o "desenvolvimento econômico que se traduz como barbárie social" conforme o enunciado por lamamoto (2015, p. 125).

A necessidade de retomar o debate sobre os direitos sociais no âmbito do Estado é emergencial, como é o caso dos cortes de gastos e financiamentos, da emenda constitucional $n^{\circ}$ 95, de 15 de dezembro de 2016 (BRASIL, 2016), que institui teto de gastos "no âmbito dos Orçamentos Fiscal e da Seguridade Social da União"; assim como, o Projeto de Lei da Câmara n 38, de 2017 - Reforma Trabalhista que foi aprovada no senado 
em novembro de 2017 (CÂMARA DOS DEPUTADOS, 2017). Ambas as ações do governo federal, entre tantas outras em curso, incidem diretamente na execução e promoção das políticas sociais, assim como, nos direitos trabalhistas, abrindo caminho para flexibilização e instabilidade da vida dos/das trabalhadores/as no Brasil.

Coloca-se frente à um processo contínuo de disputa pela efetivação de um conjunto de políticas sociais que materializam programas, projetos e serviços para efetivação dos direitos sociais, ou pela manutenção de um Estado mínimo que tem a privatização, os cortes públicos e o capital internacional como premissa. Por outro lado, as reivindicações da classe trabalhadora para além dos direitos trabalhistas, da saúde, da assistência social, da educação, da previdência social, da habitação, da cultura, entre outros, estão presentes neste contexto de lutas sociais, que muitas vezes são negligenciados pelos meios de comunicação de massa.

Pensar a comunicação nos meios midiáticos é uma tarefa que ganha espaços diferenciados ao longo do tempo, a exemplo disso é o Conselho Federal de Serviço Social referência para as/os assistentes sociais - que há mais de uma década constrói estratégias visando o fortalecimento de uma comunicação efetiva e da defesa dos direitos humanos e sociais. Tais estratégias se apresentam na terceira edição da Política de Comunicação do Conjunto CFESS/CRESS (CFESS, 2016). Importante situar que a formação em Serviço Social permite refletir sobre a importância da mídia, da comunicação, da informação e tudo que diz respeito a este campo. Principalmente em tempos que observa-se a comunicação em seu papel contraditório no processo de acesso às informações - sejam elas de ordem política, econômica, social, cultural e ambiental - tanto para o bem quanto para o mal.

Segundo a Pesquisa Brasileira de Mídia (PBM) (BRASIL, 2016), ao questionarem os/as entrevistados/as sobre quais meios utilizam para se informar, $89 \%$ dos entrevistados afirmam ver televisão, 49\% utilizam internet e 30\% escutam rádio. Esses números evidenciam a importância dos meios de comunicação no cotidiano das pessoas, onde o acesso às informações está diretamente ligado a estes meios.

Os meios de comunicação são fundamentais para a democracia de qualquer Nação, mas no Brasil a reforma do sistema de comunicação é emergente. O Jornal Le Monde Diplomatique ((BRANT, 2013, p. 25) abordou os 4 problemas graves na condição das mídias e suas concessões, quais sejam: o quase monopólio da televisão aberta; a concentração de poder dos políticos que detém concessões de televisão e rádio; a 
desigualdade no acesso à internet; e as ameaças à liberdade e à garantia de direitos na rede. A reportagem considera que historicamente a estruturação da comunicação no Brasil, objetivou o fortalecimento das redes nacionais, resultando no grande poder adquirido pelas emissoras tradicionais na ditatura militar (1964-1985) até a atualidade.

Ao trazer essa reflexão para o âmbito do Serviço Social, é preciso reconhecer que a necessidade de pensar as lutas sociais que emergem da relação entre o capital e o trabalho, fez com que a categoria de assistentes sociais a partir das suas entidades representativas se aliassem às bandeiras de luta dos movimentos sociais. Dentre as defesas da categoria, pode ser citado o envolvimento com questões como: o combate ao racismo, à LGBTfobia, a defesa da seguridade social ampliada, da legalização do aborto, da democratização da comunicação, dentre outros. Esta última pauta tem uma centralidade neste texto, pois a defesa da democratização da comunicação possibilita a análise crítica do Serviço Social para com os meios de comunicação tradicionais, como a televisão e o rádio comercial que integram o oligopólio das mídias e pertencentes à classe dominante e que, consequentemente, se constituem enquanto ferramentas de perpetuação de produção e reprodução do capital (SOARES, 2018).

Nessa condição, o Conjunto CFESS/CRESS se soma à luta pela democratização da comunicação, juntamente com o Fórum Nacional pela Democratização da Comunicação (FNDC) para pautar a regulação da mídia, a partir de uma reestruturação das concessões públicas de sinal de rádio e TV para empresas privadas que perpetuam discursos da sociabilidade burguesa e que se mostram ferramentas indispensáveis para a produção e reprodução do capital.

Na contramão das mídias tradicionais se desenvolvem as mídias alternativas que ganham força principalmente pelo advento das novas tecnologias, porém a caminhada dessas mídias ocorre há muito tempo, e como as lutas sociais, se constituem juntamente com os movimentos de resistência. Nesse sentido, as rádios comunitárias, sendo estas legalizadas ou não, se mostram ao decorrer dessa reflexão enquanto espaços que permitem a potencialização e a articulação da classe trabalhadora, tendo como característica a sua comunidade e a realidade local onde as rádios comunitárias estão inseridas. Porém, como os diversos campos da comunicação, principalmente as rádios comunitárias vivenciam a realidade do fenômeno do "coronelismo eletrônico", que segundo Nunes (2015), são normalmente emissoras que deveriam ter o caráter 
comunitário, mas são mantidas por religiões, políticos e comerciantes, que equipam e promovem o acontecimento da rádio comunitária da sua região, com a intenção de fazer sua campanha eleitoral, ou de fazer desta rádio, uma rádio comercial.

Assim sendo, considerando estas reflexões introdutórias, este artigo está organizado em mais três partes, sendo que: na primeira, traz-se o lastro teórico da reflexão situando a discussão do Estado Social e a sua relação com os meios de comunicação; na segunda, discorre-se sobre a produção de conhecimento no âmbito do Serviço Social e a temática comunicação, para dar evidência a importância desta discussão na agenda formativa e de trabalho profissional, uma vez que a defesa intransigente dos direitos humanos e, portanto, sociais, são princípios éticos e políticos da profissão; e na última, buscou-se discorrer sobre as potencialidades das rádios comunitárias enquanto mídias alternativas fomentando a importância da articulação do Serviço Social no entendimento de que estas rádios podem ser consideradas espaços estratégicos para o fortalecimento dos direitos sociais e da articulação da classe trabalhadora.

\section{Ponto de partida: o Estado Social e os meios de comunicação}

Inicia-se esta parte do artigo refletindo acerca dos meios de comunicação no contexto brasileiro e o Estado Social, o que exigiu necessariamente uma revisão teórica que pudesse elucidar a compreensão sobre a relação que existe entre os meios de comunicação e a conformação do Estado Social brasileiro. A compreensão sobre este último é destacada aqui, pois é o Estado o responsável constitucionalmente pela provisão de um conjunto de políticas, programas e serviços que devem atender as necessidades dos cidadãos e cidadãs no que diz respeito aos seus direitos sociais.

Os meios de comunicação, neste contexto, têm o papel de comunicar e informar à população como é previsto na Constituição Federal, onde se preconiza na programação, a preferência com "finalidades educativas, artísticas, culturais e informativas", a "promoção da cultura nacional e regional" e "estímulo à produção independente que objetive sua divulgação, a regionalização da produção cultural, artística e jornalística, conforme percentuais estabelecidos em lei" e "respeito aos valores éticos e sociais da pessoa e da família" (BRASIL, 1988). Porém, a realidade que se apresenta no Brasil diverge das diretrizes citadas, em que "os sistemas e mercados de comunicação são capitaneados por conglomerados que controlam os principais canais de distribuição de conteúdos 
midiáticos do Brasil." (GÖRGEN, 2017, p. 505). Assim, compreende-se que os meios de comunicação para além do controle exercido por estes conglomerados, exerce papel fundamental na formação de opinião da população brasileira, "com cunho privadocomercial" (GÖRGEN, 2017, p. 508).

O Estado brasileiro que se constitui enquanto regulador das concessões públicas dos meios de comunicação, mas que se apresenta enquanto um concessor de outorgas para a lógica privada, se empenha em manter o poder dos meios de comunicação nas mãos de poucos, mas pode-se então, se questionar: por que isso ocorre dentro do Estado brasileiro compreendido nesta produção enquanto um Estado social?

Inicialmente é preciso compreender o Estado como sendo "composto por um território, uma população e um sistema de governo capaz de exercer a soberania sobre o território e conduzir relações internacionais com outros estados." (CEPIK, 2016, p. 101). Neste sentido, os Estados se diferenciam uns dos outros tanto em relação as proporções de território, quanto à densidade populacional, tipos de sistemas de governos, até mesmo de suas capacidades de concentrações de toda ordem e ainda são "reconhecidos por todos, ou contestados por muitos, mais ou menos ricos, poderosos e desiguais." (CEPIK, 2016, p. 101).

Nessa perspectiva partindo do entendimento sobre o Estado social, este enquanto, sendo identificado a partir da "regulação estatal das relações econômicas e sociais no capitalismo, que têm nas políticas sociais uma determinação central." (BOSCHETTI, 2017, p. 23). Este posicionamento é colocado diante do movimento de construção e execução das políticas sociais nesse âmbito. Afinal, o Estado Social ao proferir a regulação econômica e social por meio das suas políticas sociais, embora muitas sejam tardiamente implementadas no Brasil, não se propõe a romper com a lógica capitalista que caracteriza a sociedade atual, "e menos ainda the atribuir qualquer intencionalidade de socializar a riqueza por meio de políticas sociais." (BOSCHETTI, 2017, p. 24).

As relações contraditórias que se estabelecem no âmbito do Estado social são inúmeras, a partir da condição destacada por Boschetti (2017), pois o Estado pode não possuir ou garantir um viés de primazia para os direitos sociais e políticas sociais universalizantes. É necessário pensar em que realidade as políticas sociais se desenvolvem, e nesse sentido, destaca-se o processo contraditório em que elas se 
inserem, pois mesmo que o "fato de assumir uma "feição" social por meio de direitos implementados pelas políticas sociais, não retira do Estado sua natureza capitalista e nem faz dele uma instância neutra de produção de bem-estar." (BOSCHETTI, 2017, p. 24).

As políticas sociais no âmbito do Estado social são fruto da luta das expressões da questão social, onde a classe trabalhadora vivencia as condições do capital, e reivindica seus direitos ao Estado que deve ser o provedor destes. Boschetti (2017) afirma que a partir destas reivindicações não há a possibilidade de se conquistar a emancipação humana do modo de produção capitalista, o que não quer dizer que os avanços no âmbito dos direitos sociais e das políticas sociais não foram avanços significativos para a classe trabalhadora, pelo contrário, "instituíram sistemas de direitos e deveres que, combinados com a instituição de tributação mais progressiva e ampliação do fundo público, alteraram o padrão de desigualdade entre as classes" (BOSCHETTI 2017, p. 25), principalmente na segunda metade do século XX.

Também é preciso destacar que o Estado, independente da sua forma - pois ele é resultado da luta de classes - apresenta aspectos que diferenciam sua ação na sociedade de acordo com as particularidades de cada uma, ou seja, a partir da sua própria formação sócio-histórica, ou seja, fruto da realidade social, mas mesmo com suas particularidades, não se extrai a gênese dessa formação, que é "sua morfologia estruturalmente capitalista." (BOSCHETTI, 2017, p. 25).

Cury ao tratar sobre a hegemonia traz que as relações de dominação ocorrem a partir da busca pelo consenso entre as classes, e que essa política de dominação implica "o aprofundamento da exploração mediante a manutenção das relações sociais" (CURY, 2000, p. 55) e que necessitam da presença do Estado para ocorrer. Afinal, é o Estado, com sua estrutura burocratizada, que não se caracteriza como sendo somente "regulador da economia e árbitro da sociedade", pois ele colabora com a manutenção geral da produção mantendo as condições para os processos de acumulação do capital.

Por outro lado, o próprio processo de acumulação e concentração gera uma série de tensões, que desafiadoramente impõem ao Estado a função de manter um certo equilíbrio político e uma forma de harmonia social que satisfaçam certos interesses das classes dominantes. O capitalismo monopolista, não prevendo e nem podendo controlar totalmente os efeitos cumulativos da reprodução ampliada, busca mecanismos políticos de controle que permitam corrigir ou atenuar os desequilíbrios decorrentes das contradições emanadas do próprio mercado (CURY, 2000, p. 55). 
Traz-se estas reflexões de Cury (2000) para elucidar que as contradições presentes na ação do Estado, demonstram que ao decorrer de seu desenvolvimento e com o amadurecimento do capitalismo, estas relações se tornam mais complexas. Iasi (2017) cita em seus estudos, o quanto ao longo da história no Brasil em diferentes contextos as promessas de gestores estatais são recorrentes, como por exemplo: a promessa do fim da miséria. Entretanto, o que parece acontecer é que "o pragmatismo reinante nos leve, um dia, a estabelecer como meta "conviver" com a miséria" (IASI, 2017, p. 221). Parece que há uma naturalização das desigualdades sociais no Brasil e muito disto deve-se a mídia que não enaltece a importância dos índices que emergem de todas as formas de violação dos direitos, não estabelecendo uma comunicação com a população brasileira, majoritariamente formada pela classe trabalhadora, que segundo Gomes (2007, p. 70):

\begin{abstract}
No caso do Brasil existe uma vasta regulamentação sobre a comunicação, mas todas voltadas para o indivíduo, os meios tradicionais e as novas tecnologias. A expressão direito à comunicação não aparece em nenhum documento. $O$ que alguns defendem é que essas legislações, como é o caso da Constituição Federal, contemplam os direitos relacionados à comunicação, sendo desnecessário uma citação direta. Os estudos na área do direito sobre comunicação não debatem o conceito desta como um direito humano.
\end{abstract}

O reconhecimento dos direitos sociais e, sobretudo, sua universalização nos sistemas de proteção social capitalista, seja em forma de bens e serviços, seja em forma de prestações sociais monetárias, possibilitou a melhoria das condições de vida, certa redução das desigualdades sociais e certa distribuição do fundo público. Mas, certamente, não desmercantilizou as relações sociais, que continuam regidas pelas relações capitalistas fundadas na produção socializada e na apropriação privada de seus resultados. Mascaro (2013) refere-se que o Estado é um fenômeno capitalista, "condensando as relações sociais específicas, a partir das próprias formas dessa sociabilidade".

Entre o Estado, o direito, a religião, a cultura, os meios de comunicação de massa, as artes e as instituições ideológicas, de modo geral, há relações que vão tanto de um eventual desconhecimento mútuo até a total implicação estrutural ou funcional (MASCARO, 2013, p. 36).

Assim, a manutenção da lógica capitalista se constrói a partir de aparatos que vão além das políticas sociais que se engendram por dentro do Estado, como é o caso dos meios de comunicação tradicionais, os quais são importantes instrumentos de 
manipulação do pensamento da população e que disseminam informações comprometidas com o ideário capitalista.

É o reconhecimento das contradições nos aspectos que competem ao Estado Social, a começar pelas concessões públicas de rádio e televisões brasileiras, que direciona para a pensar o papel fundamental dos meios de comunicação na condição da efetivação e de acesso ao direito à informação, uma vez que estes meios estão sob comando do grande capital. Fato esse que faz com que o direcionamento dos conteúdos e abordagens da realidade, sejam constantemente distorcidos e manipulados, de maneira que os meios de comunicação hegemônicos se apresentem enquanto aparelhos ideológicos à serviço do capital.

\section{A relação do Serviço Social e a Comunicação}

Com base na sistematização até aqui têm-se argumentos teóricos para adentrar no Serviço Social e sua relação com a temática da comunicação. Considerando a revisão teórica realizada para o desenvolvimento de uma investigação (SOARES, 2018), observouse que as produções ainda são mínimas, mas trazem questões extremamente pertinentes para a profissão, principalmente considerando autores tais como: Salles (2011); Ruiz (2011); Espíndola (2011); Figueiredo (2011); Correia (2011); Braz (2011), entre outros, que abordam a relação entre a comunicação e a profissão, mesmo não sendo uma literatura vasta, essa relação entre as temáticas se consolidam dentro da profissão.

A materialização da articulação da categoria profissional com esta temática da comunicação se traduz a partir da Política de Comunicação do conjunto CFESS/CRESS (CFESS, 2016) que atualmente está na sua terceira edição, e que foi construída a partir dos encontros da categoria com eixos fundantes nos princípios éticos da profissão. Eixos esses que são evidenciados na política de fiscalização e que com o tempo foi instituída a necessidade de pensar a comunicação como direito humano e a sua democratização (BRAZ,2011). “A primeira e a segunda versão, publicadas respectivamente em 2007 e 2011, foram documentos de grande importância e serviram de acúmulo para a construção da nova política." (CFESS, 2016, p. 1). O Conselho Federal de Serviço Social apresentou em 2016 a terceira edição da Política de Comunicação do Conjunto CFESS/CRESS, a partir da 44 Encontro Nacional do conjunto CFESS/CRESS. 
O conteúdo que constitui a política foi debatido entre os Conselhos Regionais de Serviço Social e o Conselho Federal pensando estratégias para "potencializar a produção e a socialização de informação entre os CRESS e o CFESS e destes com a categoria e a sociedade, na direção de reafirmar o projeto ético-político profissional". Porém os objetivos do Conjunto a partir da política ultrapassam o fazer profissional e a operacionalização das comissões de comunicação (integradas por assessores de comunicação e assistentes sociais) que compõe os CRESS e o CFESS.

Na necessidade de se pensar a totalidade que envolve a comunicação e de pensar o projeto ético-político dos assistentes sociais que ultrapassam o fazer profissional, a Política de Comunicação reitera o compromisso com a sociedade e com as lutas sociais em prol da classe trabalhadora. Nessa perspectiva o CFESS se uniu ao Fórum Nacional pela Democratização da Comunicação (FNDC) e inseriu em suas bandeiras de luta a democratização da comunicação.

Para além do debate no âmbito do trabalho profissional pautado pelo conjunto CFESS/CRESS, outras instâncias representativas da categoria construíram e constroem o debate sobre a temática da comunicação. Neste processo de busca por produções desta temática no âmbito do Serviço Social, destaca-se a obra "Mídia, Questão social e Serviço Social" (2011) que trata de temáticas que envolvem o debate da interlocução do Serviço Social com a comunicação.

Pode se dizer que esta obra enfatiza o quanto o debate sobre os meios de comunicação perpassa o pensar a profissão e constituem esse processo. Na apresentação da obra, Salles (2011) e Ruiz (2011) falam sobre a origem do livro, onde a partir da necessidade de debater a comunicação foi desenvolvido o curso de extensão "Mídia, Questão Social e Serviço Social" que foi uma ação conjunta entre o CFESS e o CRESS do Rio de Janeiro, os autores tratam que a ação extensionista objetivava debater para além do reconhecimento da importância da comunicação pela categoria, também desafios, como:

O de apreender os processos socioculturais e políticos que fazem com que as expressões da questão social sejam invisibilizadas ou criminalizadas pela mídia nacional; e b) o de reconhecer que a imagem pública do Serviço Social ainda destoa do perfil apontado pelo projeto ético-político da profissão no país (SALLES, 2011, p. 26).

Assim, o que se pensava a partir dessas necessidades da categoria, iam ao encontro da questão social e como esta é repercutida no âmbito midiático, como o 
Serviço social é visto pela sociedade e como estes processos envolvem a profissão. Os autores abordam a condição da questão social ser vista a partir do entendimento da "questão policial", em que a parte policial que veicula nos meios de comunicação parece estar completamente desalinhada das expressões da questão social, sendo que estas são as próprias expressões. Considerado pelos autores também, está a necessidade de compreender a potencialidade da mídia enquanto "objeto de questionamento e de militância político-profissional potenciais" (SALLES, 2011, p. 27).

Figueiredo (2011) trata sobre a mobilização social enquanto uma estratégia para a transformação social, pois "desenvolver um trabalho que considere estes elementos enquanto recurso de trabalho é encontrar possibilidades, na era das comunicações, para viabilizar a informação como um direito inalienável e a democracia como um valor" (2011, p. 342). Correia (2011) refere-se que "na medida em que estabelecemos alianças políticas com setores sociais que compartilham dessa utopia, esse debate é imprescindível para a formação e atualização profissional em Serviço Social (2011, p. 359).

Assim, o Serviço Social se insere no debate sobre os meios de comunicação pensando a fundamental contribuição que a profissão pode agregar na luta pela democratização da comunicação, mas também compreendendo este espaço enquanto contraditório e que vivencia correlação de forças entre os interesses da classe dominante e os da classe trabalhadora. Entende-se que o embate sobre o que veicula nos meios de comunicação incide em como a população usuária, e os próprios trabalhadores das políticas sociais compreendem o acesso aos seus direitos, por isso é fundamental o profissional considerar a articulação entre os meios de comunicação e a sociedade, pensando as potencialidades e a necessidade de reflexão sobre esses meios de comunicação.

Da condição da mobilização social Braz (2011) traz as suas contribuições ao elucidar que: "a disputa entre projetos societários passou a depender cada vez mais delas [formas de comunicação], tornando-as instrumentos obrigatórios e decisivos da luta política." (BRAZ, 2011, p. 376). Destarte, o autor desperta o debate para dois âmbitos, no caso, do lado da burguesia que sempre utilizou os meios de comunicação de massa como maneira de manter-se enquanto classe dominante, e por outro lado, os meios de comunicação contra-hegemônicos que são produtos desenvolvidos pela classe trabalhadora organizada politicamente, para se opor ao conteúdo das mídias de massa. 
Um dos exemplos a ser citado dentro destes meios utilizados pela classe trabalhadora é o Iskra, jornal criado por Lênin enquanto instrumento de fortalecimento da luta dentro da Rússia, segundo o autor "em todos eles, evidenciou-se que os meios de comunicação são, na verdade, meios de disputa de hegemonia".

\footnotetext{
O debate midiático configura-se interessante como estratégia, porque contribui justamente para a ruptura da e do isolamento, por meio do engendramento de uma resistência nacional e também internacional, via redes de comunicação descentralizadas e projetos de comunicação alternativa, contra a crise de civilização que atravessamos (SALLES, 2011, p. 29).
}

É nesta perspectiva que foi impulsionado e desenvolvido o debate sobre as rádios comunitárias, pensando às potencialidades destas dentro de suas comunidades e feitas por suas comunidades. A partir dessas análises também se compreende a importância dos profissionais de Serviço Social se inserirem no debate sobre as transformações tecnológicas da informação, pensando o uso das diferentes mídias, isso implica em profissionais que trabalham com as expressões da questão social, também falarem sobre elas e elucidarem para a população de maneira responsável sobre direitos sociais, da importância da mobilização, do olhar crítico para as questões que envolvem violência e pobreza, saindo de uma lógica que legitima o senso comum e que viola direitos. Esse movimento que deve ser feito por aqueles que trabalham com estas questões faz com que seja passada para a sociedade como um todo um pensamento crítico e uma análise da realidade que emerge a partir da relação entre o capital e o trabalho.

Salles (2011) trata sobre o fetiche da relação entre dinheiro e mercadoria que é apresentado por Marx em O Capital, entendendo que a relação entre exploração do trabalho e produção do valor, se intensifica na contemporaneidade a partir do processo de alienação, onde a invisibilização dos processos de produção dentro da sociedade de consumo ocorre de maneira exacerbada. Os meios de comunicação neste processo são parte importante dessa invisibilidade, pois os media se apropriam das chamadas consciências coletivas, incidindo na dimensão social e educativa.

Salles (2011), Ruiz (2011), Figueiredo (2011) e Braz (2011) também tratam sobre o debate sobre o âmbito da mídia, da esfera pública e da democracia, enfatizando o lugar dos meios de comunicação dentro da sociedade capitalista e da incidência desse oligopólio em âmbito mundial, que incide diretamente na constituição desta esfera pública. O debate da produção de conhecimento do Serviço Social para o viés da 
comunicação perpassa o entendimento de que o oligopólio midiático é uma realidade mundial, justificando em grande parte a subalternização da classe trabalhadora e a criminalização das movimentações que partem desses meios de comunicação, ou seja, as expressões da questão social se mostram constantemente criminalizadas e/ou invisibilizadas pelas mídias pertencentes à classe dominante.

Ruiz (2011) trata sobre experiências positivas que envolvem a defesa dos direitos humanos e a luta pela comunicação enquanto um desses direitos, como é o caso da Agência Nacional dos Direitos da Infância (ANDI), que acompanha o trabalho realizado pelas mídias de massa no Brasil em conteúdo que envolva crianças e adolescentes, e também na classificação indicativa da programação radiodifusora, também experiências que envolvem jornalistas, professores e pesquisadores da área de direitos humanos que lutam por uma comunicação que não viole os direitos humanos, o debate sobre o software livre e inclusão digital, que é uma iniciativa que luta pela democratização da internet.

Neste contexto, tratar sobre os meios de comunicação e trazer a centralidade da questão social e de suas expressões e ao mesmo tempo envolver este debate com o código de ética profissional e o projeto ético-político são trazidos nas literaturas destacadas nesta produção, como é visto em Salles (2011), Correia (2011) e Braz (2011).

Correia (2011) se refere que assumir a importância da comunicação é parte relevante da ampliação da garantia do direito à informação para os sujeitos e atores sociais. Essa defesa garante o fortalecimento da luta por direitos sociais e pelas políticas sociais e públicas, incidindo no debate sobre o controle social democrático. Correia (2011) aborda que a partir da construção desse pensar o aspecto educativo de ações que envolvem os direitos se fortalecem em algumas ações como: “adotar uma relação pedagógica baseada na discussão crítica do processo de ensino-aprendizagem e do tripé Pesquisa-Extensão-Ensino"; incentivar e inovar em projetos interdisciplinares no âmbito acadêmico, incidindo desta maneira no processo de formação de futuros assistentes sociais; a produção de materiais informativos com linguagem acessível que efetive seu alcance à todos/as; e o fomento da participação de assistentes sociais nos órgãos representativos da categoria trabalhando conjuntamente com outras profissões no desenvolvimento de materiais que fortalecem a posição da categoria frente aos debates travados dentro dela. 
Braz (2011) ao contextualizar e elucidar sobre a importância da articulação entre o Serviço Social e a comunicação, trata da importância desta para a potencialização do projeto ético-político, pois o autor defende que a articulação da categoria para debater a construção da direção política da profissão perpassou processos estratégicos de mobilização através de meios comunicacionais. A partir deste vínculo que se estabelece dentro da categoria, entendeu-se que para a consolidação do projeto ético-político seria necessário fortalecer os mecanismos comunicacionais das entidades representativas para com a categoria na defesa das políticas sociais e públicas e da democracia, da contribuição do reconhecimento da comunicação enquanto um direito e um bem público, opondo-se ao oligopólio da comunicação no Brasil, dentre outras questões, esse movimento político também consolidou processos institucionais nestas entidades, assim Braz refere que:

\begin{abstract}
A política de comunicação aprovada pelos assistentes sociais demonstra a maturidade político-profissional que se alcançou, expressa fundamentalmente na compreensão de que o Serviço Social (e os assistentes sociais) tem participação na lutas sociais por uma outra sociedade, livre de qualquer tipo de exploração e/ou dominação e que precisa, para tanto, de construir seus próprios instrumentos de luta, dentre os quais a política de comunicação se destaca (BRAZ, 2011, p. 387).
\end{abstract}

Assim, Braz (2011) defende que o Serviço Social precisa da comunicação para manter e fortalecer o norte da profissão elucidado em seu projeto ético-político, e essa defesa deve ser cada vez mais fortalecida, pois vive-se na condição do sistema capitalista a força dos movimentos conservadores de defesa do capital e da negação de direitos, essa defesa se dá como uma avalanche dentro dos meios de comunicação de massa, que devese compreender que estes estão em posse da classe dominante, como é o caso do "rombo da previdência social", na condição de culpabilização dos trabalhadores por este déficit, dentre outros debates que fortalecem a desmobilização da classe trabalhadora e a dolorosa defesa da lógica do capital por parte desta.

O que se percebe a partir destes referenciais como um todo, são os seguintes elementos em comum: o entendimento de que os meios de comunicação de massa são comandados pelas classes dominantes, destacando assim o discurso da defesa do capital; ao mesmo tempo se apresentam as possibilidades através dos meios de comunicação alternativos, e aqui se inserem as rádios comunitárias, pensando que na trajetória da luta da classe trabalhadora que sempre se utilizou destes meios para potencializar suas demandas e articulações, para a mobilização social, palavra bastante evidenciada nas 
literaturas revisadas; nessa condição, foi também fortemente tratado sobre a consolidação do projeto ético-político do Serviço Social a partir de mecanismos como os meios de comunicação, que auxiliaram na construção desse projeto, para um processo hegemônico sobre o pensar e fazer esta profissão.

Assim, pelo o que se observa nas referências socializadas neste artigo, há um reconhecimento da categoria de assistentes sociais sobre a importância da interlocução profissional com os meios de comunicação. Pode ser citado como exemplo, aqueles profissionais que estão inseridos no âmbito das políticas sociais, pois nesses espaços sócio-ocupacionais é possível ampliar este debate, alcançando os sujeitos de direitos que são usuários/as e outros/as trabalhadores/as das políticas fomentando, assim, o debate nos diversos meios comunicacionais, em especial nos alternativos.

\section{Sintonizando com as Rádios Comunitárias: Possiblidades para o Serviço Social, por que não?}

Nesta parte do texto é proposto, refletir acerca da possibilidade do Serviço Social desenvolver uma interlocução com o debate sobre a comunicação. Sintonizar como as rádios comunitárias se constituem enquanto uma dessas possibilidades, que em muitas situações possuem uma relação muito próxima com a população dos territórios onde esses meios de comunicação se inserem e, ao mesmo tempo, onde também muitos assistentes sociais atuam em diferentes projetos, programas e políticas sociais. Assim sendo, traz-se também, os princípios éticos que direcionam a profissão e que estão inseridos no código de ética profissional do/a assistente social. Dentre os deveres preconizados no documento se evidencia a importância da informação enquanto uma ferramenta estratégica para o trabalho profissional.

Entre os deveres destacados, percebe-se que para a operacionalização do trabalho é necessário que o/a assistente social garanta a "plena informação e discussão sobre as possibilidades e consequências das situações apresentadas, respeitando as decisões dos/as usuários/as", que democratize "as informações e o acesso aos programas disponíveis no espaço institucional, como um dos mecanismos indispensáveis à participação dos/as usuários/as". E que tenha ainda o compromisso de "devolver as informações colhidas nos estudos e pesquisas aos/às usuários/as, no sentido de que estes possam usá-los para o fortalecimento dos seus interesses" e que "informe à população 
usuária sobre a utilização de materiais de registro audiovisual e pesquisas a elas referentes e a forma de sistematização dos dados obtidos." (CFESS, 2012, p. 30). Esses deveres foram discutidos arduamente pela categoria, pensando estrategicamente maneiras de mobilizar, articular e incentivar a participação popular em espaços como as políticas sociais e provenientes do controle social.

A relação do Serviço Social com a discussão da comunicação no Brasil e a urgência sobre o debate da democratização da comunicação, assim como, a relação do acesso à informação em especial aos direitos sociais, é fundamental. Afinal, é no trabalho profissional do/a assistente social, orientado por um projeto ético-político comprometido com a classe trabalhadora, que se efetivará a comunicação enquanto um direito humano.

Contudo, é importante frisar que o papel social de uma rádio comunitária ${ }^{1}$, é desempenhar "um papel essencial na construção da informação e do debate nas comunidades em que atuam, como é o caso de comunidades rurais, indígenas e periféricas, muitas vezes marginalizadas" (trecho de entrevista com o locutor da rádio Coité FM à Carta Capital) (MELO, 2016).

As rádios comunitárias se constituíram historicamente em meio às disputas dentro das comunidades e se desenvolveram dentre os eixos das rádios revolucionárias, religiosas ou livres (LUZ, 2011). Ou seja, as rádios revolucionárias e seus defensores caminharam na defesa das rádios comunitárias compreendendo que estas deveriam ser aparatos que se direcionam para a crítica e a mobilização das comunidades onde estão inseridas. Haubrich (2017) refere que a comunicação comunitária está inserida em um dos segmentos da mídia alternativa, mas que se deve considerar a maneira como as rádios comunitárias se estruturam, pois muitas das emissoras que se denominam comunitárias na verdade têm caráter comercial.

A partir dessas considerações, foi compreendido que as rádios comunitárias se constituem enquanto campo de disputa, e são importantes no fortalecimento do debate sobre as políticas sociais. Partiu-se da defesa da comunicação enquanto um direito que é garantido pela Constituição Federal de 1988 em seu capítulo $\vee$ que defende a livre

1 Segundo os Dados do Setor de Comunicações do Ministério da Ciência, Tecnologia, Inovações e Comunicações, foi identificado que entre janeiro de 2016 e junho de 2017 existiam 4.775 rádios comunitárias outorgadas no Brasil, onde 414 pertencem à região do Rio Grande do Sul, totalizando 8,7\% das rádios comunitárias do Brasil. Este dado mostra o número expressivo de Rádios comunitárias no Brasil e no Rio Grande do Sul, mesmo sabendo que estas são as rádios legalizadas, e que o número de rádios comunitárias sem concessão pode exceder estes índices (BRASIL, 2017) 
expressão, com princípios do que futuramente deveria ser a lei de regulamentação dos meios de comunicação que nunca ocorreu no Brasil, e a condição de que os meios de comunicação não podem ser objetos de monopólio, sendo que este princípio nunca foi cumprido.

Compreendendo mesmo que de maneira sucinta a difícil trajetória da democracia entre os tensionamentos que se apresentam, é necessária à posição de oposição e resistência (CHAUÍ, 2002) para com a realidade que se estampa no contexto das políticas sociais. Nesta condição, trata-se de exemplos de rádios comunitárias que trazem em sua construção forte aliança com o movimento sindical, que é o caso da RádioCom da cidade de Pelotas no Rio Grande do Sul, que buscava aproximar a realidade do centro e da periferia da cidade ao apresentar o debate sobre os problemas sociais enfrentados (CONRAD, 2013).

Peruzzo (2001) ao abordar a temática da comunicação e dos movimentos populares refere sobre a importância da mobilização para com as demandas emergentes da realidade da classe trabalhadora, principalmente na década de 1980 no Brasil, onde auxiliaram na construção do debate sobre as políticas sociais e da ampliação de direitos sociais no Brasil, fazendo com que essas decisões favorecessem as mobilizações comunitárias. Para além, as expressões da questão social que emergem dessas manifestações são importantes para a tencionar o projeto político, econômico e social vigente.

Mascaro (2013) reconhece em sua obra que algumas instituições não são diretamente controladas pelo Estado, como é o caso dos meios de comunicação, e que esta autonomia pode causar "transformações nos costumes, inovações pedagógicas ou ações orgânicas de profissionais e intelectuais críticos ensejassem uma desestabilização dos padrões gerais da reprodução do capital" (2013, p.84). Porém, é necessário pensar que mesmo os meios de comunicação alternativos estão inseridos na condição estrutural do capitalismo (MASCARO, 2013).

Quando é tratado sobre as rádios comunitárias enquanto um dos meios de comunicação alternativo, mesmo em meio às fortes contradições, tem-se a intenção de fortalecer o debate sobre esses espaços, pensá-los enquanto lugares estratégicos para o debate da população como um todo, de perspectiva crítica, onde trabalhadores/as se tornam participantes do processo de debater o rádio enquanto um meio de comunicação 
com alto potencial de interatividade e de simples acesso enquanto tecnologia. Ao compreender o papel fundamental da classe trabalhadora, de seu debate, de resistência, de participação e de mobilização para a as suas demandas, ocorre o embate na condição de disputar os interesses dentro do Estado e afinar as políticas sociais com a realidade vivida por aqueles que se inserem no âmbito da seguridade social brasileira. Para instigar essa participação destaca-se que as leis que regulamentam a seguridade social (saúde, assistência social e previdência) preconizam em seus textos o direito à informação.

A previdência social que foi a primeira a ser regulamentada refere-se em seu texto: "Elaborar e manter, devidamente atualizados, os estudos, informações técnicas e outros elementos relativos à administração da previdência social, divulgando-os para conhecimento geral" (BRASIL, 1960). A política de saúde no Brasil, enquanto universal defende: "Divulgação de informações quanto ao potencial dos serviços de saúde e a sua utilização pelo usuário" (BRASIL, 1990). E a Política Nacional de Assistência Social (PNAS) preconiza: "Direito à informação, enquanto direito primário do cidadão, sobretudo àqueles com vivência de barreiras culturais, de leitura, de limitações físicas" (BRASIL, 2005).

Para ilustrar um dos elos possíveis entre a rádio comunitária, como é proposto no texto, e trazendo este debate para o âmbito do Serviço Social, partiu-se de um exemplo pesquisado em uma rádio comunitária do município de Nova Friburgo no Rio de Janeiro, onde o radialista entrevistado relatou sobre um comunicado realizado pela prefeitura da cidade cancelando a Conferência Municipal de Saúde (CMS), pois havia ocorrido préconferências, e não seria necessário realizar a CMS. O radialista argumentou que esse tipo de justificativa não poderia ocorrer, pois compreendia que as pré-conferências não anulam a CMS. A partir do momento em que a notícia chegou na rádio comunitária, o radialista acionou os órgãos competentes, como o Ministério da Saúde e o Conselho Estadual de Saúde, assim pressionando e interrompendo os planos de cancelamento sugeridos pela gestão (OLIVEIRA NETO; PINHEIRO, 2013).

Assim, reforça-se que o tensionamento em embates políticos e na defesa dos direitos da classe trabalhadora, mesmo inseridos nas relações sociais que se constroem contraditoriamente no âmbito do sistema capitalista, pensam-se as possibilidades a partir das rádios comunitárias, que têm em suas características a territorialidade, o nascimento 
nas associações comunitárias de bairro, que também estão permeadas de interesses, e que têm sua gênese na proposta da reforma agrária do ar (PERUZZO, 2001).

Trazer o Serviço Social para o âmbito das rádios comunitárias e das demais mídias alternativas é também construir caminhos para a articulação e para a luta da garantia dos direitos da classe trabalhadora, por isto a informação e o acesso a mesma, foi destacada nesta sistematização.

\section{Considerações Finais}

A intenção com esta sistematização é socializar reflexões que emergem quando relaciona-se o Serviço Social com a temática da comunicação. Sem dúvida há laços a serem estreitados entre o Serviço Social e os meios de comunicação, e neste caso, os meios alternativos, enquanto ferramentas de potencialização da defesa dos direitos sociais, assim como, das políticas sociais. Ocupar esses espaços da mídia se apresenta enquanto estratégico para a aproximação do debate sobre os direitos sociais com a sociedade, pois ficou entendido que ao decorrer da história dos meios de comunicação no Brasil, a informação majoritariamente esteve nas mãos das elites e, consequentemente, da sociabilidade burguesa.

Ao mesmo tempo, fica evidente que a classe trabalhadora historicamente se utilizou de mecanismos midiáticos para reivindicar seus direitos e articular suas lutas, assim como acontece dentro do próprio Serviço Social, que cada vez mais se utiliza de estratégias comunicacionais para dialogar com as bases da profissão sobre os posicionamentos políticos e as frentes de defesa dos direitos sociais. Por isso, compreender as rádios comunitárias enquanto uma estratégia de articulação da classe trabalhadora e trazer este debate para o Serviço Social se constitui necessário em tempos de contrarreformas e destituição de direitos, entendendo que a mídia hegemônica é ferramenta estratégica do grande capital.

Assim, ocupar os espaços nos meios de comunicação alternativos e fomentar a participação dos movimentos sociais assim como, dos sujeitos de direitos, é urgente na perspectiva de subverter a ordem das relações capitalistas que criminalizam e invisibilizam a realidade social. Para o Serviço Social, cabe compreender e reafirmar a importância da participação popular e dos processos democráticos, da construção coletiva nesses meios 
de comunicação, e ao mesmo tempo analisar criticamente as informações e posicionamentos que perpassam os meios tradicionais.

\section{Referências}

BRANT, João. O lugar da comunicação. LE Monde Diplomatique, São Paulo, Ano 7, n. 73, ago.2013.p.25. Disponível em: < https://diplomatique.org.br/o-lugar-da-comunicacao/>. Acesso em: 25 de julho de 2018.

BOSCHETTI, I. Assistência social e trabalho no capitalismo. São Paulo. Editora Cortez, 2017.

BRASIL. [Constituição (1988)]. Constituição da República Federativa do Brasil. Brasília: Presidência da Republica, 5 out. 1988. Disponível em: http://www.planalto.gov.br/ccivil_03/constituicao/constituicao.htm. Acesso em: 19 maio 2017.

BRASIL. Emenda Constitucional no 95, de 15 de dezembro de 2016. Altera o Ato das Disposições Constitucionais Transitórias, para instituir o Novo Regime Fiscal, e dá outras providências. Diário Oficial [da] República Federativa do Brasil, Brasília, DF, 16 dez. 2016. Disponível em:

http://www.planalto.gov.br/ccivil_03/constituicao/emendas/emc/emc95.htm. Acesso em: 29 out. 2017.

BRASIL. Lei ${ }^{\circ}$ 3.807, de 26 de agosto de 1960. Dispõe sobre a Lei Orgânica da Previdência Social. Diário Oficial [da] República Federativa do Brasil. Brasília, DF, 5 set. 1960. Disponível em: http://www.planalto.gov.br/ccivil_03/leis/19501969/L3807compilada.htm. Acesso em: 18 maio 2017.

BRASIL. Lei $N^{\circ} 8.080$, de 19 de setembro de 1990. Dispõe sobre as condições para a promoção, proteção e recuperação da saúde, a organização e o funcionamento dos serviços correspondentes e dá outras providências. Diário Oficial [da] República Federativa do Brasil. Brasília, DF, 21 set. 1990. Disponível em: http://www.planalto.gov.br/ccivil_03/leis//8080.htm. Acesso em: 18 maio 2017.

BRASIL. Ministério da Ciência, Tecnologia, Inovações e Comunicações. Dados do setor de comunicações. MCTIC. Disponível em:

http://sistema.mc.gov.br/DSCOM/view/Informacoes.php. Acesso em: 5 out. 2017.

BRASIL. Ministério do Desenvolvimento Social. Política Nacional de Assistência Social: PNAS 2004. Brasília, DF: MDS, nov. 2005.

BRASIL. Secretaria de Comunicação Social. Pesquisa Brasileira de mídia. Brasília, DF: Secretaria de Comunicação Social, 2016. Disponível em: http://www.secom.gov.br/atuacao/pesquisa/lista-de-pesquisas-quantitativas-equalitativas-de-contratos-atuais/pesquisa-brasileira-de-midia-pbm-2016.pdf/view. Acesso em: 19 maio 2017. 
BRAZ, M. Serviço social, comunicação e projeto ético-político. In: RUIZ, J.; SALLES, M. (org.) Mídia, questão social e serviço social. São Paulo: Cortez, 2011. p. 375-390.

CÂMARA DOS DEPUTADOS. Projeto de Lei da Câmara $n^{\circ}$ 38, de 2017. Altera a Consolidação das Leis do Trabalho (CLT), aprovada pelo Decreto-Lei no 5.452, de 1ㅇ de maio de 1943, e as Leis nos 6.019, de 3 de janeiro de 1974, 8.036, de 11 de maio de 1990, e 8.212, de 24 de julho de 1991, a fim de adequar a legislação às novas relações de trabalho. Brasília: Presidência da República, 2017. Disponível em: https://www25.senado.leg.br/web/atividade/materias/-/materia/129049. Acesso em: 25 nov. 2017.

CEPIK, M. Estado. In: FERNANDES, R.; HELLMANN, A. (org.). Dicionário crítico: política de assistência social no Brasil. Porto Alegre: Editora UFRGS, 2016. p. 101-103. Disponível em: https://www.ufrgs.br/cegov/files/pub_70.pdf. A cesso em: 6 ago. 2018.

CFESS - CONSELHO FEDERAL DE SERVIÇO SOCIAL. Código de ética do/a assistente social: Lei 8.662/93 de regulamentação da profissão. 10. ed. Brasília: CFESS, 2012.

CFESS - CONSELHO FEDERAL DE SERVIÇO SOCIAL. Política Nacional de Comunicação do Conjunto CFESS/CRESS. 3. ed. Brasília: CFESS, 2016.

CHAUÍ, M. Convite à filosofia. 12. ed. São Paulo: Editora Ática, 2002.

CONRAD, K. Rádios comunitárias e a mobilização social: um estudo sobre as estratégias comunicacionais da RádioCom FM, de Pelotas. 2013. 178 f. Dissertação (Mestrado em Comunicação) - Universidade Federal de Santa Maria, Santa Maria, RS, 2013.

CORREIA, C. Desafios da comunicação para o serviço social. In: RUIZ, J.; SALLES, M. (org.) Mídia, questão social e serviço social. São Paulo: Cortez, 2011. p. 358-374.

CURY, C. R. Educação e contradição: elementos metodológicos para uma teoria crítica do fenômeno educativo. 7. ed. São Paulo: Editora Cortez. 2000.

ESPÍNDOLA, N. Em defesa do diálogo entre a mídia rádio e o Serviço Social. In: RUIZ, J.; SALLES, M. (org.). Mídia, questão social e serviço social. São Paulo: Cortez, 2011. p. 214233.

FIGUEIREDO, K. O assistente social na era das comunicações. In: RUIZ, J.; SALLES, M. (org.) Mídia, questão social e serviço social. São Paulo: Cortez, 2011. p. 323-343.

GOMES, R. A. A comunicação como direito humano: um conceito em construção. 2007. 208 f. Tese (Doutorado em Comunicação) - Universidade Federal de Pernambuco, Recife, 2007.

GÖRGEN, J. Sistema central de mídia: conglomerados de comunicação no Brasil. In: WEBER, M. H.; COELHO, M. P.; LOCATELLI, C. (org.). Comunicação pública e política: pesquisas e práticas. Florianópolis: Editora Insular, 2017. p. 483-508.

HAUBRICH, A. Mídias alternativas: a palavra da rebeldia. Florianópolis: Editora Insular, 2017. 
IAMAMOTO, M. V. Serviço social em tempo de capital fetiche: capital financeiro, trabalho e questão social. 9. ed. São Paulo: Editora Cortez, 2015.

IASI, M. Política, estado e ideologia na trama conjuntural. São Paulo: Editora Instituto Caio Prado Junior, 2017.

LUZ, D. A saga das rádios comunitárias no Brasil. In: ENCONTRO NACIONAL DE HISTÓRIA DA MÍDIA, 8., 2011, Guarapuava. Anais [...]. Guarapuava, 2011.

MASCARO, A. L. Estado e forma política. São Paulo: Boitempo Editora, 2013.

MELO, F. C. Rádios comunitárias, entre a burocracia e a Justiça. Revista Carta Capital, São Paulo, 27 abr. 2016. Disponível em: https://www.cartacapital.com.br/sociedade/radioscomunitarias-eterna-luta-contra-a-burocracia-e-a-justica. Acesso em: 10 out. 2017.

NUNES, M. V. O Rádio como arma política no Ceará. Revista Passagens, Fortaleza, v. 6, n. 2, p. 227-243, 2015.

OLIVEIRA NETO, A.; PINHEIRO, R. O que a saúde tem a ver com rádio comunitária? uma análise de uma experiência em Nova Friburgo - RJ. Revista Ciência \& Saúde Coletiva, Rio de Janeiro, v. 18, n. 2, p. 527-536, fev. 2013. Disponível em:

http://www.scielo.br/pdf/csc/v18n2/24.pdf. Acesso em maio de 2018.

PERUZZO, C. K. Participação nas rádios comunitárias no Brasil. Rede Brasil de Comunicação Cidadã. Porto Alegre: RBC - Rede Brasil de Comunicação Cidadã, 2001. Disponível em: http://www.bocc.ubi.pt/pag/peruzzo-cicilia-radio-comunitaria-br.pdf. Acesso em: 10 abr. 2017.

RUIZ, J. Comunicação como um direito humano. In: RUIZ, J.; SALLES, M. (org.) Mídia, questão social e serviço social. São Paulo: Cortez, 2011. p. 82-102.

SALLES, M. Mídia e questão social: o direito à informação como ética da resistência. In: RUIZ, J.; SALLES, M. (org.) Mídia, questão social e serviço social. São Paulo: Cortez, 2011. p. 33-82.

SOARES, J. Rádios comunitárias: as potencialidades para a promoção da informação sobre os direitos sociais. 2018. 123 f. Dissertação (Mestrado em Política Social e Serviço Social Instituto de Psicologia) - Universidade Federal do Rio Grande do Sul, Porto Alegre, 2018.

Recebido em: 21/02/2019

Aceito em: 11/11/2019 